Florida International University FIU Digital Commons

FIU Electronic Theses and Dissertations

University Graduate School

3-25-1997

\title{
The effect of three positions of shoulder flexion on grip strength
}

John David Canyock

Florida International University

DOI: 10.25148 /etd.FI14052561

Follow this and additional works at: https://digitalcommons.fiu.edu/etd

Part of the Physical Therapy Commons

\section{Recommended Citation}

Canyock, John David, "The effect of three positions of shoulder flexion on grip strength" (1997). FIU Electronic Theses and Dissertations. 2032.

https://digitalcommons.fiu.edu/etd/2032

This work is brought to you for free and open access by the University Graduate School at FIU Digital Commons. It has been accepted for inclusion in FIU Electronic Theses and Dissertations by an authorized administrator of FIU Digital Commons. For more information, please contact dcc@fiu.edu. 
FLORIDA INTERNATIONAL UNIVERSITY

Miami, Florida

THE EFFECT OF THREE POSITIONS OF SHOULDER FLEXION ON GRIP

STRENGTH

A thesis submitted in partial satisfaction of the requirements for the degree of

MASTER OF SCIENCE

IN

OCCUPATIONAL THERAPY

by

John David Canyock

1997 
To: Judith Blucker

College of Health

This thesis, written by John David Canyock, and entitled The Effect of Three Positions of Shoulder Flexion on Grip Strength, having been approved in respect to style and intellectual content, is referred to you for judgement.

We have read this thesis and recommend that it be approved.

Alma Abdel-Moty

Paulette Jơhnson

Pamela Shaffner, Major Professor

Date of Defense: March 25, 1997

The thesis of John David Canyock is approved.

Dean Judith Blucker

College of Health

Dr. Richard L. Campbell

Dean of Graduate Studies

Florida International University, 1997 
ACKNOWLEDGEMENTS

I would like to thank each member of my committee members for their insight, reassurance and patience throughout this entire process. I also want to give a special thanks to my wife, Sarah, for her unwavering support and unending encouragement. 


\author{
ABSTRACT OF THE THESIS \\ THE EFFECT OF THREE POSITIONS \\ OF SHOULDER FLEXION ON GRIP STRENGTH \\ by \\ John David Canyock \\ Florida International University, 1997 \\ Miami,Florida \\ Pamela Shaffner, Major Professor
}

This study investigated the effect of shoulder position on grip strength in 30 female students from Florida International University. A Jamar dynamometer was used to measure the grip strength in three testing positions $(0,90$ and 135 degrees of shoulder flexion with full elbow extension). The highest mean grip strength measurement was found at 135 degrees of shoulder flexion, followed by 0 degrees and then 90 degrees. An ANOVA indicated that there was a significant difference between at least two of the three positions. A Fisher's LSD post hoc test indicated that mean grip strength at 135 degrees of flexion was significantly higher than at 0 and 90 degrees of flexion. 
I. INTRODUCTION ........................... 1

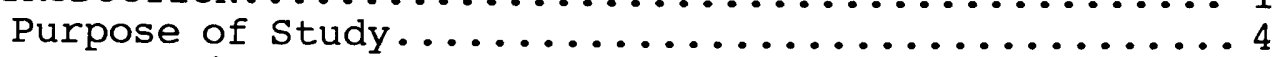

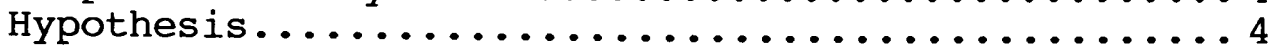
Statement of Problem/ Significance of study....... 5 Definitions........................... 6

II. REVIEW OF THE LITERATURE..................... 8

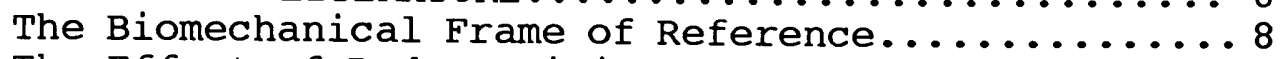
The Effect of Body Position on Strength .......... 11

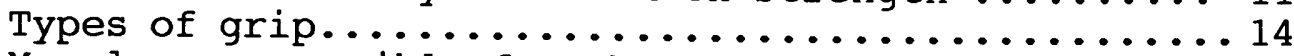

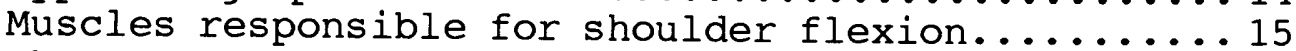

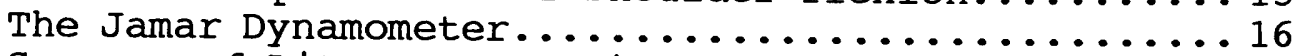

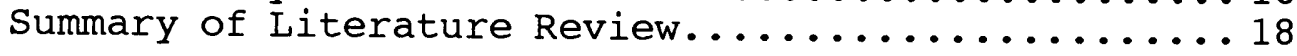

III. METHODOLOGY .............................. 19

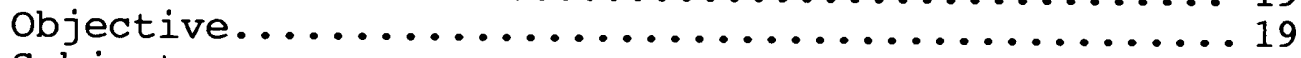

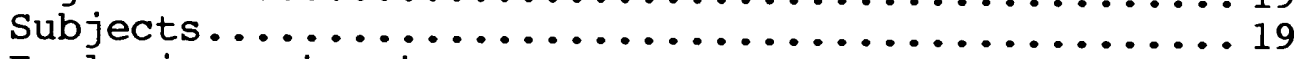

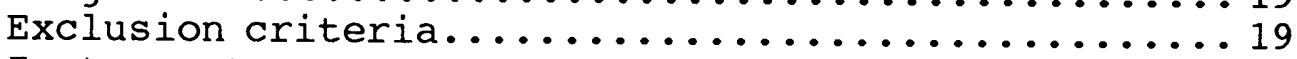

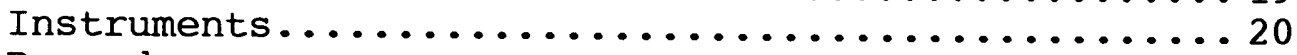

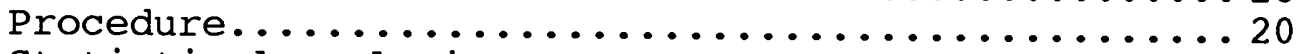

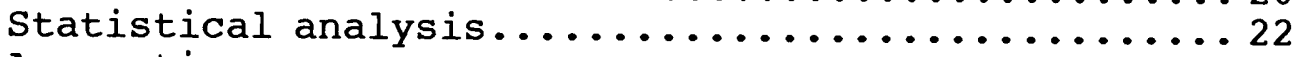

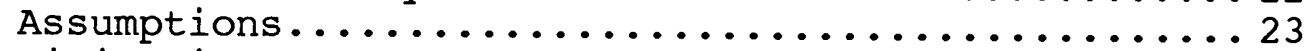

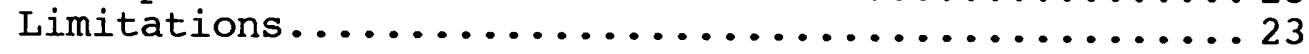

IV. $\quad \operatorname{RESULTS} \ldots \ldots \ldots \ldots \ldots \ldots \ldots \ldots \ldots \ldots \ldots \ldots \ldots \ldots \ldots \ldots \ldots$

V. DISCUSSION........................... 27

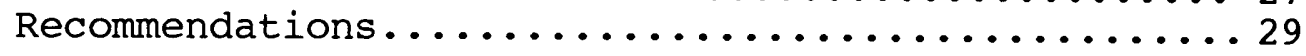

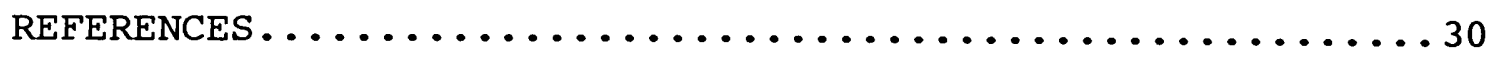

APPENDICES .................................. 35

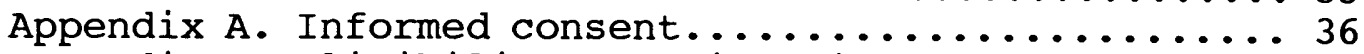

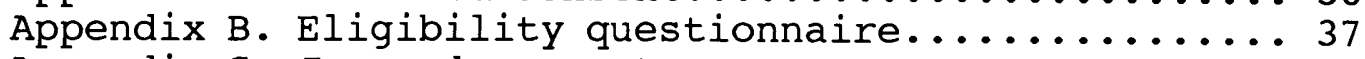

Appendix C. Jamar dynamometer.................. 38

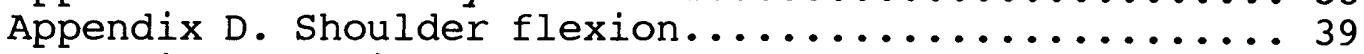

Appendix E. Goniometer....................... 40

Appendix F. Elbow flexion.................... 41 


\section{List of Tables}

Table 1

Means and Standard Deviations of Mean Grip Strength by Shoulder Position and Order................. 24

Table 2

Analysis of Variance on Mean Grip Strength by Order and

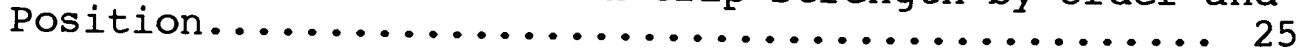

Table 3

Means and Standard Deviations by Shoulder Position... 26 
Introduction

Men and women truly do explore their environment through the use of their hands. The versatility of the hand allows us to perform necessary daily activities from personal hygiene to the performance of work and money earning activities. For example, Cynkin (1990), in a description of a woman making a pie, makes these interesting observations:

She must have good neuromuscular control and coordination to pour and cut to exact specifications. She must also have integrated the concepts of size, weight, pressure, and coldness and thus be able to transmit her knowledge of the size of a small pea to her hands and eyes as they obediently cut and assess to the required dimensions. The dough reaches a perfect consistency and is accurately shaped, not only because of the coordination and dexterity in her arms and hands, but also because the gentle pressure called for is monitored by the messages from her sensitive hands and fingers to her brain, which directs the strength of the muscular response. The control of her movements is dependent also on the stability of her head, neck, and trunk and, if she is standing, on the stability of her lower limbs as well. (p. 5)

The treatment of the upper extremity is extremely important to all occupational therapists who work with physically disabled individuals. The incidence of upper 
extremity injuries is significant and accounts for about one third of all injuries. The nearly 16 million upper extremity injuries that occur annually in the United States result in 90 million days of restricted activity and 12 million visits to physicians (Kasch, 1990).

It is therefore important for occupational therapists to assess hand function, and one such source of information on the functional capabilities of the hand is a grip strength measurement. Grip strength has been found to be correlated with overall strength (Niebuhr \& Marion, 1990), has been used to assess general strength in order to determine work capacity (Gilbert \& Knowlton, 1983), and has been useful in indicating the extent of injury and disease and the potential for rehabilitation (Peterson, Petrick, Connor, \& Conklin, 1989). Grip strength, when measured properly and consistently, provides objective and quantifiable information regarding upper extremity function.

Measurement of grip strength is also an important component of rehabilitation because it helps to establish a baseline for treatment and it is a measure of the effectiveness of therapy (Fraser \& Benten, 1983). Knowledge of body positioning and grip strength becomes extremely useful as occupational therapists and other rehabilitation professionals develop treatment plans, assess home and work environments, and perform task analysis, ergonomic analysis, and work simplification in order to reduce stress on body parts.

Occupational therapists provide individuals with assistance in establishing or reestablishing skills and 
abilities needed to return to work. Occupational therapists also assist non-disabled individuals with injury prevention at the workplace through ergonomic analysis(Jacobs, 1995). The ergonomic analysis consists of three major areas: work methods, workstation design and worker posture, and handle and tool design. Work method analysis determines what the worker must do in order to successfully perform the task. This can be done by observation or videotape, and special attention is given to count repetitive movements in a given cycle. The therapist must also consider the speed, pace and duration of repetitive movements required by the worker (Jacobs, 1995).

Workstation analysis examines the relationship between the worker and the workstation, with special concern for required postures and movements. An occupational therapist can provide the client with information on how to reduce stress on their body at the workstation. For instance, an occupational therapist can recommend proper chair height, back support, head angle, arm support, keyboard location, leg room, and work document location (Jacobs, 1995).

Analysis of handle and tool design is also important, because poor tool design is a common cause of hand and wrist disability. For example, it is important to try to maintain the wrist in neutral during tasks, and tool handles should be built up enough so that only the distal phalanges of fingers and thumbs overlap to assist with grip (Jacobs, 1995). 


\section{Purpose of the Study}

The purpose of this study was to investigate the effect of three different shoulder positions on grip strength. Knowledge of body positioning and grip strength is important for occupational therapists and other rehabilitation professionals both clinically and in the home and work environment. Clinically, the relationships between upper extremity positioning and grip strength are extremely important to the occupational therapist for accurate measurement of grip strength. The occupational therapist is constantly utilizing knowledge of the effect of body positioning on function during the assessment and treatment of patients.

\section{Hypotheses}

Null hypothesis

Ho: There will be no difference in mean grip strength among the three shoulder positions $(0,90,135$ degrees of flexion) with the elbow in complete extension.

\section{Alternative hypothesis}

Ha: There will be a difference in mean grip strength between at least two of the shoulder positions with the elbow in complete extension. 


\section{Statement of the Problem/Significance of the study}

The current protocol for grip strength testing recommends that the subject be seated with shoulder adducted and neutrally rotated, the elbow flexed at 90 degrees, and the forearm and wrist in neutral (Fess \& Moran, 1981). A Jamar Dynamometer (see Appendix A) was recommended as the best instrument to measure grip strength by the California Medical Association Committee. The American Society of Hand Therapists recommends that the second handle position be used and that a mean of three successive trials be recorded (Fess \& Moran, 1981).

The problem is that in a clinical setting it may not be possible to follow the recommended testing procedures due to physical limitations in the patient. Since the existing literature indicates that there are differences in an individual's grip strength when the upper extremity is placed in different positions (Balogun et al., 1991; Kraft and Detels, 1972; Kuzala and Vargo, 1992; Mathiowetz, Rennels, and Donahoe, 1985; Pryce, 1980; Richards, Olsen, \& PalmiterThomas, 1996; Su, Lin, Chien, Cheng, \& Sung, 1994; Teraoka, 1979;), it would be prudent for the therapist to continue testing grip strength consistently in the same position throughout the treatment of that individual, even if the physical limitations making the recommended testing position impossible are no longer present. Therefore, knowledge of the relationships between upper extremity positioning and grip strength are extremely valuable to the occupational therapist. 
This information is also used in the process of treatment planning in the clinic. A therapist may be able to maximize a patient's grip strength for functional activities through positioning of the upper extremity. Patients who are in work hardening programs and subsequently discharged back to work could also be instructed on how to maximize grip strength and reduce the possibility of occupational overuse disorders through the use of positioning ( $\mathrm{Su}, \mathrm{Lin}, \mathrm{Chien}$, Cheng, \& Sung, 1994). This knowledge enhances the therapist's ability to assist the client in improving the client's productivity, which in turn increases the clients' employability (Matheson et al., 1985).

\section{Definitions}

1) Shoulder flexion with elbow extension- (see Appendix D) this is the motion that begins with the arm straight down at the side, elbow straight, and occurs when the arm is brought forward in front of body in the sagittal plane (Norkin \& Levangie, 1992)

2) Goniometer- (see Appendix E) a calibrated device designed to measure the arc or range of motion of a joint (McDonough, Jr., 1994). In this study a universal goniometer was used, consisting of two plastic arms, one stationary and one moving .

3) Dynamometer- an instrument for measuring the degree of muscular power (McDonough, Jr., 1994)( See Appendix C) $4)$ Grip- the type of grip used by the subjects is called a power grip, defined by Norkin and Levangie (1992) as sustained finger flexion that varies in degree with size, 
shape and weight of the object. Thumb may serve as an additional surface to the finger-palm vise by adducting against the object, or it may be removed from the object. In this study the thumb was adducted against the dynamometer. 5 ) Shoulder adduction- adduction is defined as movement of a limb toward the median line, or beyond it (McDonough, Jr., 1994) .

6) Neutral rotation- a shoulder is neutrally rotated when it is in neither rotated toward the midline of the body, nor rotated away from the midline of the body (McDonough, Jr., $1994)$. 


\section{Chapter 2}

Review of the Literature

The Biomechanical Frame of Reference.

Biomechanics is the science of the action of forces, internal or external, on the body. The biomechanical frame of reference applies the mechanical principles of kinetics and kinematics to the movement of the human body (Pedretti \& Pasquinelli, 1990). This approach includes techniques of evaluation and treatment that use the application of forces to the body and employ principles of physics, such as levers and torque, to select and direct the forces appropriately. This includes muscle strength testing, joint measurement, therapeutic exercise, and orthotics (Pedretti \& Pasquinelli, $1990)$.

The biomechanical frame of reference defines function as the capacity to perform movements as they pertain to the accomplishment of tasks (Kielhofner,1992). This capacity for motion includes joint range of motion, muscle strength and endurance. Strength is the ability of muscles to produce tension to maintain postural control and move body parts. Endurance is the ability to sustain over time the work required to do a particular task (Kielhofner, 1992) .

Disorder or dysfunction exists when everyday occupational functioning is affected by an alteration in range of motion, strength or endurance (Kielhofner, 1992). Limitations in joint range of motion may be due to joint structural damage, edema, spasticity, skin tightness, or contractures secondary to immobilization. Muscle weakness can result from disuse or disease affecting muscle 
physiology. Diseases or trauma of the lower motor neurons, the spinal cord, or peripheral nerves will result in deinnervation of muscles. This may result in atrophy of the muscle, which will reduce the muscle mass and decrease the tension producing ability of the muscle (Kielhofner,1992). Muscles may also become weaker due to muscle diseases that directly affect the muscle itself, such as muscular dystrophy, or as a result of prolonged disuse or immobilization.

Dutton (1995) maintains that there are four assumptions for the practice of occupational therapy using the biomechanical perspective. The first assumption is that purposeful activity can be used to treat the loss of range of motion, strength, and endurance. The second assumption is that once strength, range of motion, and endurance are regained, the patient automatically regains function. The third is the principle of rest and stress. The body must rest to heal itself, then peripheral structures must be stressed to regain range, strength and endurance. The final assumption is that biomechanics is best suited for patients with an intact central nervous system. The biomechanical approach demands controlled voluntary movement, which is not possible for individuals with central nervous system damage (Pedretti \& Pasquinelli, 1990).

The biomechanical frame of reference provides some insight as to how the position of the shoulder and elbow would affect grip strength. The power grip used by individuals being tested by the Jamar dynamometer involves the long flexor and extensor muscles of the fingers and thumb 
that originate from the radius and ulna of the forearm and medial and lateral epicondyle of the humerus (Richards, Olsen, \& Palmiter-Thomas, 1996). Because these muscles, like all muscles, have an optimal length at which they produce a maximal contraction, any external lengthening or shortening of these fibers could decrease their ability to maximally contract (Norkin \& Levangie, 1992). This optimal length of tension is produced when the muscle is stretched approximately ten percent beyond resting length. A muscle is at resting length when it is unstimulated and no external forces are acting on it (Lehmkuhl \& Smith, 1983).

Many studies have shown that mean grip strength is greater when the elbow is extended than when the elbow is flexed at 90 degrees (see Appendix F) (Balogun et al, 1991, Kazula \& Vargo, 1992, and Su et al, 1994). One possible explanation for these findings involves this length-tension relationship. The flexor digitorum superficialis is the only muscle responsible for finger flexion that crosses the elbow joint. When the elbow is flexed, the flexor digitorum superficialis is placed in a shortened position. This affects the length-tension relationship, and may reduce the muscle's ability to produce a functional contraction (Kendall \& McCreary, 1983). The more flexion in which the elbow is placed, the higher the mechanical disadvantage of the flexor digitorum superficialis (Kuzala \& Vargo, 1992).

The relationship between the muscles of the shoulder and back and grip strength has been the source of much speculation. No muscles responsible for grip are found in the shoulder, yet proximal muscles in the human body very 
often have an effect on distal muscles. Eggers (1992) states in her book addressing the treatment of adults with hemiplegia that in order to achieve functional improvement distally one has to treat the arm as a functional unit. While facilitating correct movements proximally in the head, shoulder and trunk, distal functions are automatically encouraged.

Su et al. (1994) speculate that the results of their study, which found that grip strength is strongest when the shoulder is flexed to 180 degrees (see Appendix B), may indicate that the synergistic muscles of the back and shoulder may be able to act to their best advantage when the shoulder is in 180 degrees of flexion. Kuzala and Vargo (1992) found that the subjects in their study reported that they felt stronger in 0 degrees of elbow flexion (they held the shoulder in 0 degrees of flexion throughout their study), and posited that this may be due to the fact that this position places the shoulder in a very stable position, possibly allowing compensation or overflow to occur.

\section{The Effect of Body Position on Grip Strength}

Several studies have addressed the importance of body posture on grip strength. Teraoka(1979) tested the effect of three body positions on grip strength: supine, standing and sitting. The results indicated that grip strength was highest in standing, followed by sitting and then supine. Balogun et al (1991) found similar results in their study investigating grip strength in sitting and standing. They found that grip strength was stronger in standing when 
compared to sitting regardless of whether the elbow was positioned at 90 degrees flexion or full extension.

Pryce (1980) performed a study in which the elbow of the subjects was held in 90 degrees flexion, and the position of the wrist was held in nine different positions. The results indicated no difference in grip strength with the wrist positioned in 0 and 15 degrees ulnar deviation or 0 and 15 degrees extension or any combination of these. Grip strength scores were significantly lower with the wrist in 15 degrees of wrist flexion or 30 degrees ulnar deviation or both. Similar results were found by Kraft and Detels (1972) regarding grip strength and wrist position. They found no significant difference in grip strength for the wrist positioned in 0,15 or 30 degrees of extension and significantly lower scores with the wrist in 15 degrees of flexion.

There is some incongruity in the existing literature regarding the effect of elbow position on grip strength. Mathiowetz, Rennels, and Donahoe (1985) found that grip strength scores were higher when the elbow was positioned in 90 degrees of flexion when compared to full elbow extension. In a subsequent study, Kuzala and Vargo (1992) investigated the effect of four different elbow positions $(0,45,90$ and 135 degrees of flexion) on grip strength. They found that grip strength was strongest in complete extension, and became progressively lower as the elbow was placed in more degrees of flexion. More credence can probably be placed in the Kuzala and Vargo study, as they had a larger sample (46 compared to 30 for Mathiowetz, et al.), and their sample 
contained both males and females. A subsequent study by Su et al.(1994) also found that mean grip strengths were higher when the elbow was in complete extension than when the elbow was in 90 degrees of flexion, supporting the findings of Kuzala and Vargo.

The position of the forearm has also been found to be influential on grip strength. Richards et al. (1996) found that grip strength with the forearm supinated was the strongest, followed by the neutral position. Forearm pronation produced the weakest grips.

Only one study has explored the effect of shoulder position on grip strength. Su et al.(1994) investigated grip strength on 160 ( 80 men and 80 women) Chinese subjects with the shoulder in 0,90 and 180 degrees of flexion and the elbow fully extended. They also tested the subjects in 0 degrees of shoulder flexion and 90 degrees of elbow flexion. The results indicate that grip strength when the shoulder is at 180 degrees of flexion was significantly higher than grip strength at positions of 0 and 90 degrees of shoulder flexion. Also, all positions of shoulder flexion with the elbow extended were significantly higher in grip strength than the position of 0 degrees shoulder flexion and 90 degrees elbow flexion. No significant difference in grip strength was found between 0 degrees shoulder flexion with the elbow fully extended and 90 degrees shoulder flexion and full elbow extension. In women, surprisingly, there was no significant difference in grip strength between the positions of 90 and 180 degrees of shoulder flexion and full elbow extension. 


\section{Types of Grip}

There are essentially two general types of functional hand patterns described in the literature; power grasp and precision handling (Strickland, 1987). In broad terms, the power grip is a combination of strong thumb flexion and adduction with powerful flexion of the ring and small fingers on the ulnar side of the hand. Delicate precision functioning is performed in the tripod use of pinch between the thumb, index, and long finger (Strickland, 1987).

The power grip has been further classified into three varieties; (1) cylindrical grip, (2) spherical grip, and (3) hook grip (Norkin \& Lavangie, 1992). The cylindrical grip is the most frequently used power grip, and is also the grip used when measuring grip strength with a dynamometer.

Cylindrical grip is almost exclusively performed by the finger flexors in order to maintain grasp on an object. The function in the fingers is performed largely by the flexor digitorum profundus (FDP), especially in the dynamic phase of finger flexion. In the static phase, the flexor digitorum superficialis (FDS) assists when the intensity of the grip requires greater force. Cylindrical grip is also frequently accompanied by wrist ulnar deviation and extension, both of which optimize the force of the finger flexors. The performance of power grip is not done by the extrinsic muscles alone. The dorsal interossei have been shown to play an equally important role in strong grip. The lumbricals, despite their location, do not contribute to finger flexion. This is consistent with their role as interphalangeal joint extensors (Norkin \& Lavangie, 1992). 
The most common position of the thumb in cylindrical grip is around the object, then flexed and adducted to act as a vise. This is performed by the thenar muscles and the flexor pollicis longus (FPL). The activity of the thenar muscles will vary with the width of the web space and with increased pressure or resistance. The magnitude of activity of the adductor pollicis is a characteristic that distinguishes the power grip from the precision handling (Norkin \& Lavangie, 1992).

The muscles of the hypothenar eminence (abductor digiti minimi, opponens digiti minimi, and flexor digiti minimi) are also usually active in the power grip. The abductor digiti minimi flexes and abducts the little finger. The opponens digiti minimi and flexor digiti minimi are more variable, but generally reflect abduction and rotation of the large joint in the first metacarpal (Norkin \& Lavangie, 1992).

\section{Muscles responsible for shoulder flexion}

Shoulder flexion, or the ability to elevate the arm overhead in the sagittal plane (plane which separates the body into a right and left half), is actually a combination of scapulothoracic, scapulohumeral (glenohumeral), and trunk motions. This is commonly referred to as scapulohumeral rhythm.

The specific muscles used in the glenohumeral portion of shoulder flexion include the anterior deltoid and supraspinatus as the primary movers. The pectoralis major, coracobrachialis, and biceps brachii are secondary shoulder flexors and assist the primary shoulder flexors. Abduction 
and upward rotation of the scapula is performed by the serratus anterior and trapezius muscles (Hislop \& Montgomery, 1995). The combination of scapular and humeral movement results in what is commonly held to be a maximum range of elevation of 180 degrees, and an overall ratio of 2 degrees of glenohumeral motion to 1 degree of scapulothoracic motion (Norkin \& Lavangie, 1992).

In the first 60 degrees of shoulder flexion an inconsistent amount of of scapular motion takes place relative to glenohumeral motion. During this early phase, motion takes place primarily in the glenohumeral joint as the scapula seeks a position of stability in relation to the humerus. With increasing range, the scapula increases its contribution, approaching a 1:1 ratio with the glenohumeral movement, until the glenohumeral joint again increases its contribution again at the latter part of range (Norkin \& Lavangie, 1992) .

\section{The Jamar Dynamometer}

The Jamar dynamometer was selected as the instrument to measure grip strength in this study based on the recommendation by a California Medical Association Committee that it is the best measure of grip strength (Fess \& Moran, 1981). Mathiowetz et al. (1984) also found in a study that the Jamar dynamometer had the highest calibration accuracy of any grip strength instrument tested. The Jamar dynamometer measures pounds and kilograms of force. The American Society of Hand Therapists recommends that a mean of three grip strength trials be recorded, and that the second of five 
handle positions be used (Fess \& Moran, 1981).

Mathiowetz et al. (1984) investigated the validity, inter-rater reliability, and test-retest reliability of the Jamar dynamometer. The validity of the Jamar dynamometer was determined by comparing its calibration accuracy with that of the Preston hand dynamometer and the Jamar digital dynamometer. This was done by suspending known weights from the center of the hand pieces. Mathiowetz et al. report that neither of the two new dynamometers achieved the accuracy of the standard Jamar dynamometer, which was found to be + or 3\%. This is higher than the manufacturer reports, which is + or - 58 (Mathiowetz et al., 1984).

A Pearson product moment correlation was used to assess the correlation between two raters using the Jamar dynamometer, and the results indicate significant correlation coefficients of .996 for the right hand, and .999 for the left hand (Mathiowetz et al., 1984). In order to determine test-retest reliability, a Pearson product-moment correlation was used to assess the correlation of two separate observations of hand strength tests administered a week or less apart. The correlation coefficients for the right hand were found to be as follows: .788 for one trial, .862 for the mean of two trials, .883 for a mean of three trials and .822 for the highest score of three trials. As the results indicate, the highest test-retest reliability is found when using a mean of three trials (Mathiowetz et al., $1984)$. 


\section{Summary of Literature Review}

The existing literature indicates that the position of the body does have an effect on grip strength. The position of the wrist (Pryce, 1980), elbow (Kuzala and Vargo, 1992), and forearm (Richards et al., 1996) have been found to be influential on an individual's ability to produce a maximum grip strength.

The relationship between shoulder position and grip strength has been ignored somewhat by researchers. Su et al.(1994) investigated grip strength on 160 (80 men and 80 women) Chinese subjects with the shoulder in 0,90 and 180 degrees of flexion and the elbow fully extended. The results indicated that grip strength when the shoulder is at 180 degrees of flexion was significantly higher than grip strength at positions of 0 and 90 degrees of shoulder flexion in men. In women, however, there was no significant difference in grip strength between the positions of 90 and 180 degrees of shoulder flexion and full elbow extension. 
Methodology

Objective

The objective of this study was to investigate the effect of three positions of shoulder flexion $(0,90,135)$ on grip strength. The following hypotheses were tested:

Null hypothesis

Ho: There will be no difference in mean grip strength among the three shoulder positions $(0,90,135$ degrees of flexion).

Alternative hypothesis

Ha: There will be a difference in mean grip strength between at least two of the shoulder positions. Subjects

The subjects for this study consisted of 30 volunteer females from the Occupational Therapy Department at Florida International University. The subjects were required to complete a brief questionnaire, in which they were asked to report to the best of their knowledge that they had no history of physical disorders which may have affected their hand function, that they were between the ages of 18 and 36 years old, and that they were right-hand dominant. Those who were found to be appropriate subjects upon completion of the questionnaire were then tested for grip strength.

Exclusion criteria

1. Individuals diagnosed with a physical disorder (muscular, neurologic or orthopedic) which might affect their hand function or affect their ability to flex their shoulder.

2. Individuals who were left-hand dominant. 
3. Individuals not between the ages of 18-36 years old. 4. Males.

\section{Instruments}

The Jamar dynamometer, placed in the second handle position, was used to measure grip strength. The dynamometer had never been used, and was assumed to be factory calibrated.

Two goniometers were used to determine the amount of shoulder flexion before the grip strength trials were performed. One goniometer was glued at an angle of 90 degrees, and another in the 135 degree position. These two goniometers were used for every subject.

\section{Procedure}

The subjects were given a short questionnaire regarding their medical history, hand dominance and age (see Appendix B). Eligible subjects were then told that they would be involved in a study regarding grip strength and the position of the shoulder, and were required to read and sign a consent form (see appendix A).

The subjects were positioned in standing, with their shoulder adducted and neutrally rotated and elbow fully extended for each of the three test positions: 1) 0 degrees shoulder flexion, 2) 90 degrees shoulder flexion, and 3) 135 degrees shoulder flexion. For the positions of 90 and 135 degrees of shoulder flexion a goniometer was used to ensure accuracy in the testing position. The goniometer was placed with the fulcrum at the individual's acromial process, the proximal (stationary) arm along the midaxillary line of the thorax, and the distal (moving) arm aligned with the lateral 
midline of the humerus (Norkin \& White, 1995). The subjects' feet were approximately shoulder width apart. The subjects were instructed to squeeze the dynamometer as hard as they could on every trial. A mean of three trials in each position of shoulder flexion was used for statistical analysis.

In the statistical analysis, "order" refers to the 6 possible orders of shoulder position in which the subjects could have been tested. For example, in this study 5 subjects were tested using the order 1-2-3, with 1 corresponding to shoulder position 1 ( 0 degrees shoulder flexion), 2 corresponding shoulder position 2 (90 degrees shoulder flexion), and 3 corresponding to shoulder position 3 (135 degrees shoulder flexion). Five other subjects were tested in the order of 1-3-2, and 5 others in the order of 2$1-3,5$ more in the order of $2-3-1,5$ more in the order of $3-$ 1-2 and 5 more in the order of 3-2-1.

The sequence of the three test positions was balanced to avoid any order effect. To balance the sequence, each of the six possible testing orders was used exactly five times in a predetermined sequence. The first, seventh, thirteenth, nineteenth, and twenty-fifth subjects received the order of 1-2-3; the second, eighth, fourteenth, twentieth and twentysixth subjects received the 1-3-2 order; the third, ninth, fifteenth, twenty-first, and twenty-seventh subjects received the 2-1-3 order; the fourth, tenth, sixteenth, twenty-second and twenty-eighth subjects received the 2-3-1 order; the fifth, eleventh, seventeenth, twenty-third and twenty-ninth subjects received the 3-1-2 order; and the sixth, twelfth, 
eighteenth, twenty-fourth and thirtieth subjects received the 3-2-1 order. Balancing the orders allowed statistical analyses to be used to determine if the order of shoulder positions had an effect on the mean grip strength of each position. For example, it could be determined if the mean grip strength scores for subjects who started with their shoulder in 0 degrees of shoulder flexion were higher than the mean grip strength scores for subjects who started in 135 degrees of shoulder flexion.

Statistical Analysis

A mixed analysis of variance ( 6 orders by 3 trials) with the 6 possible orders as the between subjects factor and shoulder position $(0,90,135$ degrees) as the within subject factor was then conducted to determine if there were any order or interaction effects. This ANOVA determined if there were any statistically significant differences among the 6 possible orders $(1-2-3,1-3-2,2-1-3,2-3-1,3-1-2$ and 3-2-1) without regard to position and if there was any interaction between order and shoulder position. This was used to indicate the presence of a fatigue or any other effect. With no significant order or trial differences found, a repeated measures analysis of variance was performed to determine if any statistically significant differences existed between the mean grip strength scores of the three positions. A Fisher's LSD post hoc test was then performed in order to determine which positions were statistically different from one another. 
Assumptions

1. The Jamar dynamometer was calibrated.

2. Subjects performed the grip trials to the best of their maximum ability.

3. Subjects accurately reported about their health status.

4. Subjects understood the instructions given to them.

Limitations of the Study

A convenience sample was used for this study, which limits the generalization of the results to the population at large. Another factor affecting the generalization of the results was that the sample was small, consisting of only 30 subjects, and only right-hand dominant females between the ages of 18 and 36 were used.

In addition, the subjects in this study did not have a history of physical problems which might affect their hand and shoulder function. The use of healthy individuals in the study was necessary for comparative and ergonomic reasons (Richards, Olsen \& Palmiter-Thomas, 1996), however, the relationships between grip strength and body position may differ for physically impaired individuals.

Another limitation was that during this study the position of the wrist was not strictly controlled. As Su et al (1994) observed during their study, individuals in this study naturally held their wrists in some degrees of extension during maximal grip strength effort. 
Results

Before addressing the hypothesis that that there would be a statistically significant difference in mean grip strength scores between at least two of the three shoulder positions, the order and interaction effect was investigated. The means and standard deviations of mean grip strength measured in pounds of force for the six possible orders of shoulder position were calculated and are presented in Table 1 .

Table 1

Means and Standard Deviations of Mean Grip Strength by Shoulder Position and Order degree

\begin{tabular}{|c|c|c|c|c|c|c|}
\hline \multirow[t]{2}{*}{ order } & \multicolumn{2}{|c|}{0} & \multicolumn{2}{|c|}{90} & \multicolumn{2}{|c|}{135} \\
\hline & $\mathrm{m}^{*}$ & $S D$ & $m *$ & $S D$ & $m *$ & SD \\
\hline $1,2,3$ & 72.14 & 12.63 & 69.16 & 11.14 & 70.14 & 11.47 \\
\hline $1,3,2$ & 61.58 & 6.77 & 60.26 & 8.29 & 62.94 & 8.70 \\
\hline $2,1,3$ & 75.48 & 7.72 & 72.88 & 9.50 & 75.96 & 6.76 \\
\hline $2,3,1$ & 64.48 & 14.36 & 64.08 & 13.41 & 66.50 & 13.05 \\
\hline $3,1,2$ & 70.74 & 22.50 & 67.54 & 15.03 & 74.80 & 20.11 \\
\hline $3,2,1$ & 64.36 & 10.06 & 66.12 & 12.09 & 70.00 & 11.55 \\
\hline
\end{tabular}

A mixed analysis of variance with the 6 orders as the between subjects factor and shoulder position $(0,90,135$ degrees) as the within subject factor was performed. There were no statistically significant differences among the 6 
orders for mean grip strength across positions, $F(5,24)=0.73$, $\mathrm{p}<.605$.

There was not a significant interaction between order (first, second, or third) and position $(0,90,135$ degrees) on mean grip strength, $F(10,48)=1.18, p<.335$. Therefore, order did not affect the grip strengths overall or for some orders differently than others (see Table 2).

There was a significant difference among the three shoulder positions with regard to mean grip strength, $F(2,48)=7.95, \mathrm{p}<.002$ (see Table 2).

Table 2

Analysis of Variance on Mean Grip Strength by order and Position

\begin{tabular}{lrrcc}
\hline Source & df & MS & F & p-value \\
\hline Order & 5 & 336.00 & 0.73 & .605 \\
Error 1 & 24 & 457.35 & & \\
Position & 2 & 86.40 & 7.95 & $.002 * *$ \\
Order by & & & & .335 \\
$\quad$ position & 10 & 12.82 & 1.18 & \\
Error 2 & 48 & 10.87 & &
\end{tabular}

$* * p<.01$

Since this data indicated that there was a significant difference among the mean grip strengths of the three shoulder positions, a Fisher's LSD post hoc test at a .05 significance level was performed in order to determine where 
the differences existed among the three shoulder positions. The results indicated that the mean grip strength for the shoulder position of 135 degrees of flexion was significantly higher than the positions of 0 and 90 degrees of shoulder flexion. No significant difference on mean grip strength was observed between the shoulder positions of 0 and 90 degrees ( see Table 3 ).

Table 3

Mean and Standard Deviation by Shoulder Position

\begin{tabular}{cccc}
$\begin{array}{c}\text { shoulder position } \\
\text { (degrees) }\end{array}$ & $\mathrm{n}$ & $\begin{array}{c}\mathrm{m} \\
\text { (pounds of force) }\end{array}$ & $\mathrm{SD}$ \\
\hline 0 & 30 & 68.13 & 13.20 \\
90 & 30 & 66.67 & 11.46 \\
135 & 30 & 70.06 & 12.38
\end{tabular}

Note: Means joined with a line are not significantly different, $\mathrm{p}<.05$.

The hypothesis that there would be a statistically significant difference in mean grip strength between at least two of the three shoulder positions was supported by this study (see Table 2). The mean grip strength score was significantly higher when the shoulder was placed in 135 degrees of flexion and full elbow extension than when placed in 0 or 90 degrees of shoulder flexion and full elbow extension. 


\section{Chapter 5}

Discussion

The results of this study support the recommendation of the American Society of Hand Therapists (Fess \& Moran, 1981) that arm positioning should be standardized for hand strength testing. Also supported is the recommendation that individuals who were not tested in the recommended testing position continue to be consistently tested in the same alternative position throughout their treatment.

This study also affirms that individuals who lack grip strength can be instructed in body positioning techniques in order to maximize their ability to grip objects. This is useful clinically, as well as for the purpose of increasing an individual's ability to perform activities of daily living and leisure activities. For example, an elderly individual may be instructed to incorporate shoulder flexion into activities requiring grip strength, such as opening a jar. Although holding an arm overhead for the purposes of increasing grip strength may not be practical for some activities, the knowledge that grip strength may increase as shoulder flexion increases has many potential benefits.

One area where the knowledge of the relationship between shoulder flexion and grip strength is beneficial is in the area of work related rehabilitation, such as work hardening. It is in the areas of symptom control and job modifications that the information obtained by this study is particularly important. The identification of the proper way to position the shoulder in order to maximize grip strength will enable the therapist to instruct the client on 
strategies to decrease the symptomology of pain and overuse syndromes.

This knowledge is also useful to the therapist in providing tool or job modifications for the client. Perhaps widening the grip of a tool or placing a frequently used object overhead rather than on the desk directly in front of the client would place the client in a more efficient position for that task if grip strength is a primary concern. The results of this study are similar to the results found by su et al.(1994) in their study investigating shoulder position, elbow position and grip strength. They found that the mean grip strength scores for all subjects (male and female) were significantly higher at 180 degrees of shoulder flexion and full elbow extension than at 0 or 90 degrees shoulder flexion and full elbow extension. The results of this study differ from su et al., when female subjects are singled out. The results of this study indicated that mean grip strength in females was significantly higher at 135 degrees of shoulder flexion and full elbow extension than at 0 or 90 degrees of shoulder flexion and full elbow extension. Su et al., however, found no significant difference in mean grip strength between the positions of 90 and 180 degrees of shoulder flexion in women. However, they did not study angles of shoulder flexion between 90 and 180 degrees, and it is possible that a nonlinear relationship exists between shoulder flexion and grip strength in women. 


\section{Recommendations}

Future studies are recommended to investigate the results of grip strength measurements of previously ignored angles of shoulder flexion(e.g. 45 degrees), with both the dominant and non-dominant limbs and in males and females. Future studies may also replicate this study with males in order to determine if any gender differences are present, and with different age groups.

Future studies are also recommended with female subjects being tested in positions of shoulder flexion ranging from 90 to 180 degrees. The results of $\mathrm{su}$ et al. (1994) indicated no significant difference in mean grip strength between the positions of 90 and 180 degrees of shoulder flexion in women. However, the results of this study found a significant increase in mean grip strength in 135 degrees of shoulder flexion when compared to both 0 and 90 degrees of shoulder flexion. Further research involving other degrees of shoulder flexion could indicate if a nonlinear relationship exists between mean grip strength and shoulder position in women. Another interesting area of research is the relationship between mean grip strength and shoulder position in individuals with different ages.

It may also be interesting to investigate the effects of mean grip strength and shoulder position in individuals who are not physically healthy, such as those individuals with hand or shoulder injuries. 
Balogun J.A., Akomolafe C.T., \& Amusa L.O.(1991). Grip strength: Effects of testing posture and elbow position. Archives of Physical Medicine and Rehabilitation, 72, 280283.

Cynkin, S., \& Robinson, A.M..(1990). Occupational therapy and activities health: Toward health through activities. Boston: Little, Brown \& Company.

Dutton, R. (1995) . Clinical reasoning in physical disabilities. Baltimore: Williams \& Wilkins.

Eggers, O. (1992). Occupational therapy in the treatment of adult hemiplegia. Oxford: Butterworth-Heinemann.

Fess, E.E., \& Moran, C.(1981). Clinical assessment recommendations. Indianapolis: American Society of Hand Therapists.

Fraser, C. \& Benten, J. (1983). A study of adult hand strength. British Journal of Occupational Therapy, 10, 296299 . 
Gilbert, J. \& Knowlton, R.(1983). Simple method to determine sincerity of effort during a maximal isometric test of grip strength. American Journal of Physical Medicine, 62, 135-144.

Hislop, H. J. \& Montgomery, J. (Eds.) (1995). Daniels and Worthingham's muscle testing. Philadelphia: W.B. Saunders.

Jacobs, K. (1995). Preparing for return to work. In Trombly, C. A. (Ed.), Occupational therapy for physical dysfunction (pp. 329-349). Baltimore: Willims \& Wilkins.

Kasch, M. C. (1990). Acute hand injuries. In L. W. Pedretti \& B. Zoltan (Eds.), Occupational therapy: Practice skills for physical dysfunction (pp. 477-506). St. Louis: C.V. Mosby •

Kendall F.P., \& McCreary, E.K.(1983). Muscles, testing and function. Baltimore: Williams \& Wilkins.

Kielhofner, G. (1992). Conceptual foundations of occupational therapy. Philadelphia: F.A. Davis.

Kraft, G.H., \& Detels, P.E. (1972). Position of function of the wrist. Archives of Physical Medicine and Rehabilitation, $66,69-74$. 
Kuzala, E.A., \& Vargo, M.C. (1992). The relationship between elbow position and grip strength. American Journal of Occupational Therapy, 46, 509-512.

Lehmkuhl, L.D. \& Smith, L.K.(Eds.).(1983). Brunnstrom's clinical kinesiology (4th ed.). Philadelphia: F.A. Davis.

Matheson, L., Ogden,L., Violette, K. \& Schultz, K.(1985) Work hardening: Occupational therapy in industrial rehabilitation. American Journal of Occupational Therapy, 39, $314-321$.

Mathiowetz, V., Rennels, C., \& Donahoe, L.(1985). Effect of elbow position on grip and key pinch strength. Journal of Hand Surgery, 10A, 694-697.

Mathiowetz, V., Weber, K., Voland, G. \& Kashman, N. (1984). Reliability and validity of grip and pinch strength evaluations. Journal of Hand Surgery, 9A, 222-226.

McDonough, Jr., J.T.(Ed.).(1994) Stedman's concise medical dictionary illustrated (2nd ed.). Baltimore: Williams \& Wilkins.

Niebuhr, B., \& Marion, R. (1990). Voluntary control of submaximal grip strength. American Journal of Physical and Medical Rehabilitation, 69, 96-101. 
Norkin, C.C. \& Levangie, P.K. (Eds.).(1992). Joint structure and function: A comprehensive analysis. Philadelphia: F.A. Davis.

Norkin, C.C. \& White, D.J. (Eds.).(1995). Measurement of joint motion; A quide to goniometery (2nd ed.). Philadelphia: F.A. Davis.

Pedretti, L.W., \& Pasquinelli,S. (1990). A frame of reference for occupational therapy in physical dysfunction. In L. W. Pedretti \& B. Zoltan (Eds.), Occupational therapy: practice skills for physical dysfunction (pp. 1-17). St. Louis: C.V. Mosby •

Petersen,P., Petrick, M., Connor, H., \& Conklin, D. (1989). Grip strength and hand dominance: Challenging the $10 \%$ rule. American Journal of Occupational Therapy, 43, 444-447.

Pryce, J.C. (1980). The wrist position between neutral and ulnar deviation that facilitates the maximum power grip strength. Journal of Biomechanics, 13, 505-511.

Richards, L.G., Olson, B. \& Palmiter-Thomas, P.. (1996). How forearm position affects grip strength. American Journal of Occupational Therapy, 50, 133-138.

Smith, P.(1990). Work hardening. In L. W. Pedretti \& B. Zoltan (Eds.), Occupational therapy: Practice skills for physical dysfunction (pp. 272-281). St. Louis: C.V. Mosby. 
Strickland, J.W. (1987). Anatomy and kinesiology of the hand. In E. E. Fess \& C. A. Philips (Eds.). Hand splinting: Principles and methods ( pp. 1-42). St. Louis: C.V. Mosby.

Su, C., Lin, J., Chien, T., Cheng, K. \& Sung, Y.(1994). Grip strength in different positions of elbow and shoulder. Archives of Physical Medicine and Rehabilitation, 75, 812815.

Teraoka, T. (1979). Studies on the peculiarity of grip strength in relation to body positions and aging. Kobe Journal of Medical Science, 25, 1-17. 


\section{Appendices}




\section{Informed Consent}

The Effect of Three Positions of Shoulder Flexion on Grip Strength

I freely and voluntarily consent to be a participant in the research project entitled The Effect of Three Positions of Shoulder Flexion on Grip strength to be conducted at Florida International University during the Fall Semester, 1996, with John D. Canyock as Principal Investigator. I have been told that this experiment will last approximately 20 minutes.

I understand that the purpose of this study is to investigate the effect of shoulder position on grip strength.

I understand that I will be required to fill out a brief questionnaire in order to determine eligibility, and if found eligible, I will be asked to perform nine trials of grip strength, three trials in each of three positions. I also understand that each grip strength trial is to be performed to my maximal ability.

I understand that there are no known risks or benefits involved in my participation in this experiment. I have been told that my responses will be kept strictly confidential, and all scores will be identified only by a subject number, and my performance will not be revealed to anyone without my express permission.

I understand that I may withdraw my consent and discontinue participation in this research project at any time with no negative consequences. I have been given the right to ask questions concerning the procedure, and any questions have been answered to my satisfaction.

I understand that if $I$ desire further information about this research I should contact John D. Canyock at (954) 3499215. I have been offered a copy of this informed consent form.

I have read and I understand the above.

$$
\text { Participant's signature }
$$

Date

I have explained and defined in detail the research procedure in which the participant has agreed to participate, and have offered $\mathrm{him} / \mathrm{her}$ a copy of this consent form. 
Appendix B

FORM TO DETERMINE ELIGIBILITY
THE EFFECT OF THRICIPATION IN THE STUDY TITLED
ORE POSITIONS OF SHOULDER FLEXION ON
GRIP STRENGTH

1. Sex M $\quad$ M $\quad F \quad \square$

2. Hand dominance Right $\square \quad$ Left $\square$

3. Are you between the ages of 18 to 36 years? Yes $\square$ No

4. Do you currently have any physical conditions that would effect your ability to perform a maximum hand grip?

Yes $\square$ No $\square$

Please make sure that the appropriate box is checked for each question.

Thank you very much for your time! 


\section{Appendix C}

Jamar dynamometer

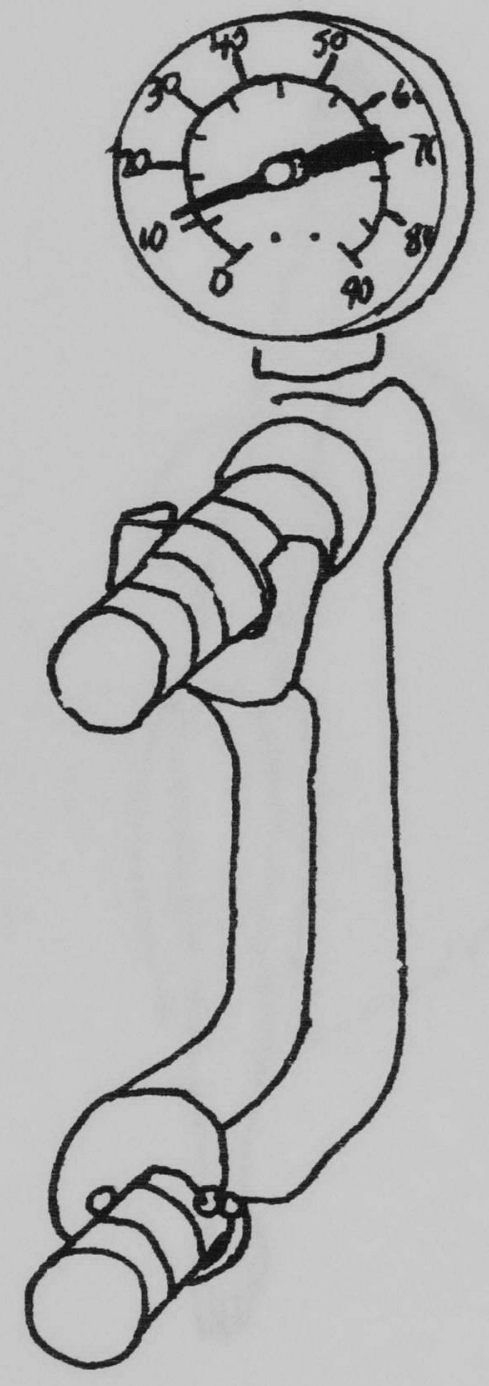




\section{Appendix D}

Shoulder flexion

Picture indicates range starting at 0 degrees shoulder flexion and ending at approximately 180 degrees of shoulder flexion. 0 degrees is when the arm is straight down at the person's side; 180 degrees is when the arm is parallel with the body directly overhead; 90 degrees is when the arm is straight in front of the body, making a right angle with the
trunk.

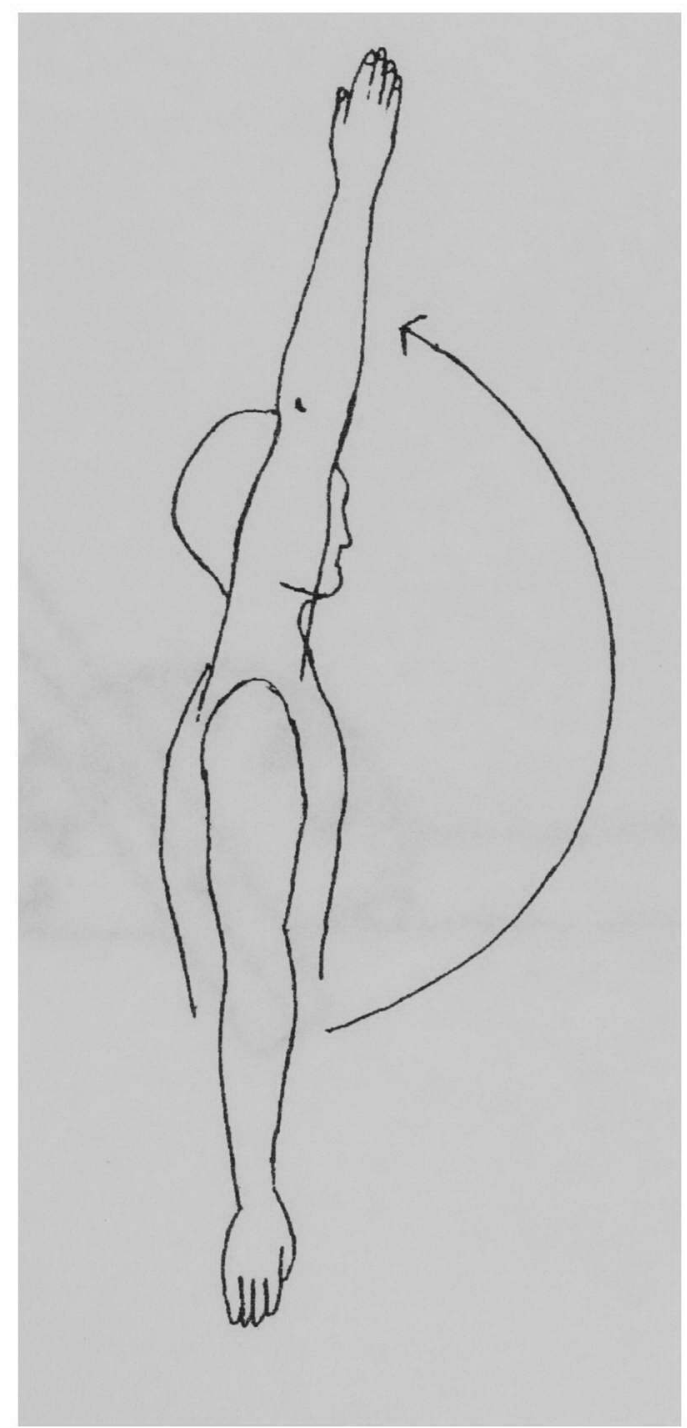


Appendix E

Goniometer; A is the moving arm, B is the stationary arm

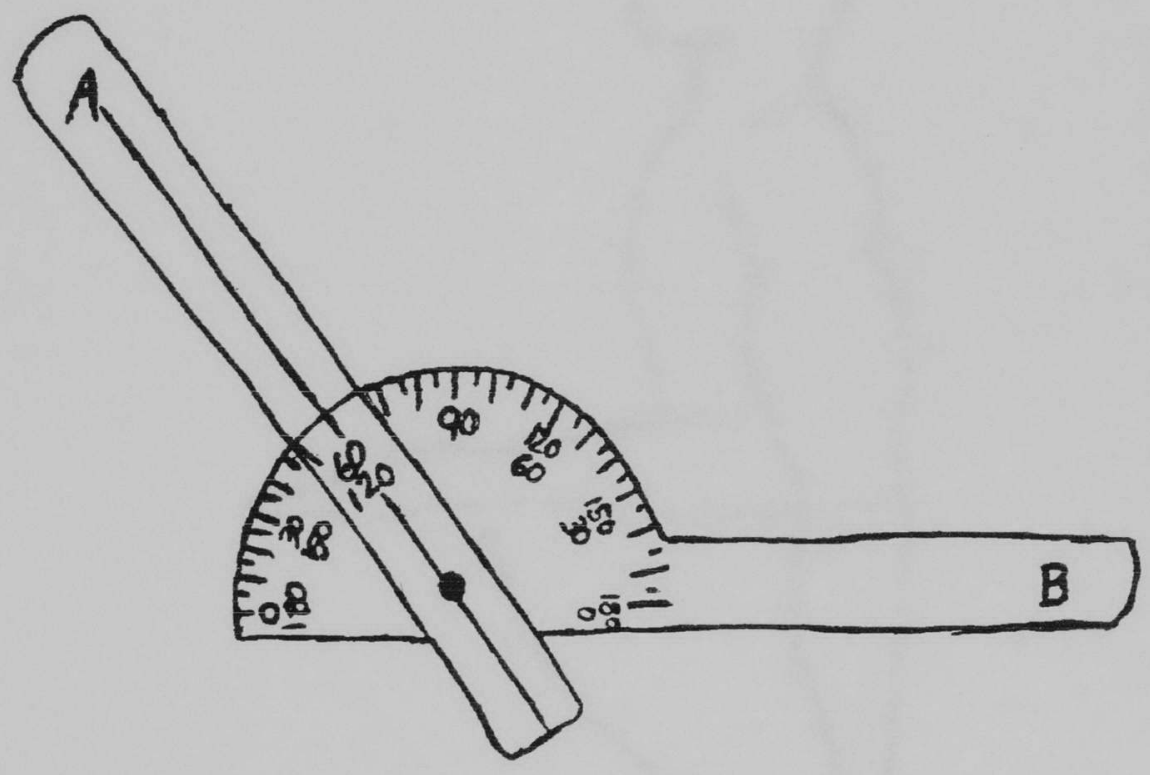


Appendix F

Elbow flexion at 90 degrees, forearm in neutral

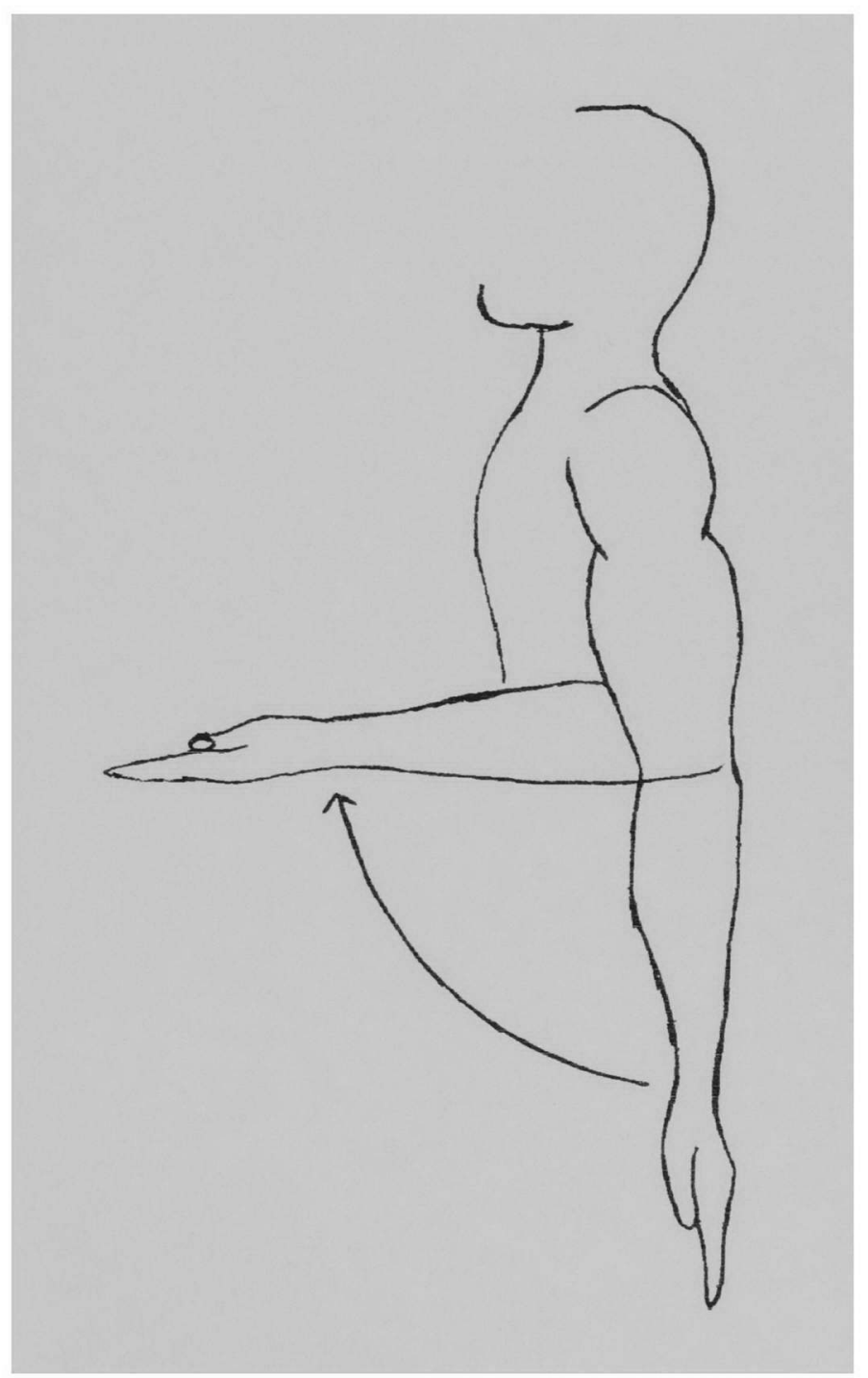

